\title{
Anesthesia of the geriatric equine
}

This article was published in the following Dove Press journal:

Veterinary Medicine: Research and Reports

3 August 2012

Number of times this article has been viewed

\section{Reza Seddighi \\ Thomas J Doherty \\ Department of Large Animal Clinical Sciences, College of Veterinary Medicine, Veterinary Medical Center, University of Tennessee, Knoxville, TN, USA}

\begin{abstract}
Advancements in veterinary medicine have resulted in an increased number of geriatric horses being presented for medical or surgical procedures that require general anesthesia. Due to the physiological changes associated with aging and the likelihood of concurrent disease conditions, the geriatric equine is at an increased risk during anesthesia. The main physiological changes associated with aging, and their impact on anesthesia, are discussed in this review.

Keywords: geriatric, equine, anesthesia
\end{abstract}

\section{Introduction}

Aging is not simply the passage of time, but a physiological, irreversible, and progressive process characterized by degenerative changes in the structure and functional reserve of organs and tissues, ${ }^{1}$ and can be defined as the loss of ability to adapt to a changing environment. ${ }^{2}$ Recent advances in veterinary medicine have increased the number of geriatric horses being presented for surgical or diagnostic procedures that require general anesthesia. Older horses are more likely to suffer from gastrointestinal emergencies, dental disease, neoplasia, sinus infections and ethmoidal hematomas, esophageal choke, and ocular problems. Data from Colorado State University Veterinary Teaching Hospital reported an increase in the percentage of horses 15 years or older being admitted for treatment, from $3 \%$ in 1973 to $12 \%$ in $2000 .^{3}$

The characterizations of age include the chronological age, or how many years an animal has been alive; the physiologic age, or how well the animal is functioning in comparison to a younger animal; and the demographic age, or how the animal compares chronologically with other animals of the same species. ${ }^{3}$ Clearly, due to the presence of concomitant or age-related diseases and environmental factors, there is a large variability in physiological status among the geriatric population. Additionally, horses may be considered different from humans or small animals as they need to remain physically active in their day-to-day existence; therefore, the term functional age is used to take into account the horse's use. ${ }^{4}$

The age at which a horse is considered aged is unclear, and depends on many factors. As a general guideline based on the chronological age, animals in the last $25 \%$ of the predicted life span for the species and breed are considered aged. Based on the average life span of horses and ponies ( 25 and 30 years, respectively), ${ }^{5}$ studies have considered horses to be geriatric at 20 years of age. ${ }^{6-8}$
Correspondence: Reza Seddighi

2407 River Dr, Knoxville,

TN 37996, USA

Tel +l 8659478387

Fax + I 8659745773

Emailmrsed@utk.edu submit your manuscript | www.dovepress.com

Dovepress

http://dx.doi.org/10.2147/VMRR.S34162
Veterinary Medicine: Research and Reports 2012:3 53-64

(C) 2012 Seddighi and Doherty, publisher and licensee Dove Medical Press Ltd. This is an Open Access article which permits unrestricted noncommercial use, provided the original work is properly cited. 


\section{Physiology of aging}

Although increasing age should not be considered a disease state per se, aging impedes the body's ability to cope with stress; consequently, aging individuals undergo physiological changes that may impact how they respond to anesthesia. ${ }^{9,10}$ Generally, in aged humans and animals, the physiological reserve and therefore, the ability of the body to maintain homeostasis decreases. Almost every body system is affected by aging, and many of these changes may affect the pharmacokinetics and pharmacodynamics of anesthetic drugs.

Most information on the physiology of aging is based on research performed on laboratory animals and humans. Although little is known specifically about the effects of aging in horses, there is no reason to suspect that horses differ from other species in this regard. It seems that no single cause is responsible for aging - aging is considered to be a multifactorial process, ${ }^{11}$ and many processes may interact simultaneously. ${ }^{12}$

\section{Theories of aging}

A number of theories have been formulated to explain the aging process, and can be categorized as evolutionary, molecular, cellular, and systemic theories. The evolutionary theory states that aging results from a decline in the force of natural selection, and longevity is a trait to be selected only if it is beneficial for fitness. The molecular theory proposes that senescence is caused by changes in gene expression, ${ }^{13}$ and that aging primarily results in damage to genetic material. The cellular theory encompasses theories relating to cellular and telomere senescence, free-radical damage to lipids, proteins, and DNA, and apoptosis subsequent to genetic events or genome crisis. The system-based theory of aging ascribes the aging process to a decline in the function of essential organs, such as in the neuroendocrine and immune systems.

Overall, mitochondrial dysfunction and oxidative stress are considered the two main interdependent mechanisms responsible for cellular damage and aging. Oxidative stress, initiated and propagated by various free radicals, not only damages the phospholipid, protein, and DNA molecules within the cell, but also modulates cell signaling pathways and gene expression patterns. ${ }^{14}$

\section{Aging and the nervous system}

In humans, aging causes a decrease in neural density and loss of up to $30 \%$ of brain mass by the age of 80 years. ${ }^{1}$ In a study of the brains of horses aged 7-23 years, significant microscopic changes, that appeared to be similar to those described in elderly people, were observed. These changes were indicative of neuronal damage and depletion, and arterial wall degeneration. ${ }^{15}$ Similar nervous system changes may be responsible for cognitive dysfunction in elderly humans. ${ }^{16,17}$ Although it is difficult to identify cognitive dysfunction in horses, it has been stated that older horses respond more slowly to stimuli than do younger horses. ${ }^{5}$

In elderly humans, cerebral blood flow is reduced by $10 \%-20 \%$, in response to a decrease in cerebral metabolic rate and decreased cerebral mass. There is a depletion of neurotransmitters including catecholamines, serotonin, and acetylcholine. Dopamine uptake sites, transporters, and their concentration are decreased, as are cortical serotonergic, alpha-2, beta adrenergic, and gamma-aminobutyric acid (GABA) binding sites, and this may affect memory and motor function. ${ }^{1,18}$ Depletion of nervous system neurotransmitters and receptor density has not been evaluated in elderly horses; however, the response of the cardiovascular system to inotropic agents was reported to be similar to that in younger animals. ${ }^{19}$

The peripheral nervous system goes through ageassociated changes including loss of motor, sensory and autonomic fibers, a decrease in afferent and efferent conduction velocities, and progressive decline of signal processing rate. A decrease in the efficiency of nerve to muscle coupling, and the number of muscle cells innervated by an axon, may lead to denervation and muscle atrophy. The responsiveness of autonomic end organs is decreased in elderly people, despite an increase in plasma epinephrine and norepinephrine concentrations. ${ }^{1}$ However, in a study on old beagles, aging did not alter the responsiveness of postsynaptic adrenergic and nonadrenergic receptors in the skeletal-muscle vasculature of the canine hind-limb, in comparison with young animals. ${ }^{20}$ In the same study, the expression of adrenergic and nonadrenergic receptors in skeletal muscle arteries was also largely unaffected by aging. Thus, animals may differ from humans with regard to peripheral nervous system changes.

Human studies have indicated only subtle changes in blood-brain barrier function in geriatrics, ${ }^{21}$ nevertheless, studies in humans and animals indicate a decrease in the minimum alveolar concentration (MAC) of inhalational anesthetics with advancing age. ${ }^{22,23}$ The decrease in MAC may be due to several mechanisms including pharmacodynamic and pharmacokinetic alterations. ${ }^{24}$ For instance, increased blood/ gas solubility of inhalational anesthetics and some biochemical alterations such as lower plasma albumin concentration in geriatrics may have a role..$^{22,25,26}$ The anesthetic MAC has not been studied in geriatric horses; however, a study in dogs 
indicated a decrease in the MAC of isoflurane in older dogs, and this has been ascribed to changes in N-methyl-D-aspartate (NMDA) receptor binding. ${ }^{27}$

Postoperative cognitive dysfunction (POCD) has been described in up to $50 \%$ of human patients undergoing anesthesia, though most seem to recover with time. Increasing age, duration of anesthesia, a second operation, postoperative infections, and respiratory complications are risk factors for early POCD, but age was found to be the only risk factor for late POCD. ${ }^{28,29}$ Although there is no evidence for the occurrence of POCD in geriatric horses, some forms of POCD may be expected to occur in geriatric horses because anesthetic complications, such as hypoxemia and hypotension, are common in this species.

There is no specific protocol for the prevention of anesthetic-related insults to the nervous system; however, it is plausible that maintaining perioperative homeostasis as close to normal as possible may minimize the risk of central nervous imbalances resulting from general anesthesia.

\section{Aging and the cardiovascular system}

Some anomalies, such as valvular heart disease, are more prevalent in older horses; whereas, myocardial disease and pericarditis are not. ${ }^{30,31}$ Many of these abnormalities are well tolerated clinically, and are not necessarily associated with an increased risk of death; but, in a proportion of older horses, they may lead to signs of severe cardiac dysfunction. It should also be noted that horses with congenital lesions, such as ventricular septal defect or patent ductus arteriosus, may not develop signs of heart failure until later years. ${ }^{30}$ In a prospective cohort study in horses, it was reported that although the prevalence of all causes of death increased with age, cardiovascular deaths did not occur in horses younger than 15 years of age, and the prevalence of fatality due to cardiovascular diseases was $5.1 \%$ in the $15-23$-year-old group and $8.5 \%$ in the 24 -year-old and older group. ${ }^{32}$

In humans, aging results in an overall decrease in the tonic influence of the parasympathetic nervous system, a decline in the responsiveness of beta receptors, and the replacement of compliant cardiac and vascular tissue by a stiff, fibrotic tissue. These changes blunt chronotropic and inotropic responses of the heart, and impair diastolic filling. Consequently, the ability of the older patient to cope with stress is compromised. ${ }^{33,34}$ Equine hearts have not been studied as thoroughly, but fibrous scarring of the left ventricular apex is reported to occur in $60 \%$ of hearts from horses older than 20 years of age. ${ }^{35}$ Decreased ventricular compliance decreases diastolic filling, increases end-diastolic pressure, and makes the heart volume sensitive and volume intolerant, and may affect cardiac output. ${ }^{1,36}$ However, the degree to which aging is associated with a decrease in cardiac output and stroke volume at rest is controversial. Decreases of up to $5 \%$ per decade in these parameters have been described in humans and, at the age of 80 years, are decreased by $50 \%$ when compared to a 30-year-old. ${ }^{1,34}$

Functional cardiac studies in horses have demonstrated that maximal heart rate $\left(\mathrm{HR}_{\max }\right)$ and aerobic capacity decline with age..$^{37,38}$ The decline in $\mathrm{HR}_{\max }$ may limit maximal cardiac output and, thus, maximal oxygen consumption $\left(\mathrm{VO}_{2 \max }\right)$ and the ability to perform exercise. A decline in $\mathrm{VO}_{2 \max }$ and exercise capacity with aging has been reported in horses. ${ }^{37}$

\section{Valvular heart diseases}

Valvular heart disease is the most common form of cardiac disease in the horse, with an overall prevalence of $23 \%$, and the prevalence seems to be greater in horses 16 years of age or older. ${ }^{39}$ Aortic valve pathology accounts for $82 \%$ of valvular abnormalities, and the greatest incidence of aortic regurgitation is in horses aged 15-20 years. ${ }^{40}$ Horses with aortic insufficiency also appear to be at risk of developing supraventricular and ventricular arrhythmias. These arrhythmias are rarely recognized on physical examination, and require ambulatory and exercising electrocardiographic studies to document their presence. ${ }^{30}$ Other arrhythmias, such as ventricular premature beats or ventricular tachycardia, may reflect myocarditis. ${ }^{41} \mathrm{~S}-\mathrm{T}$ segment depression has been reported in horses with chordae tendineae rupture, and may indicate myocardial ischemia. ${ }^{31}$ The prevalence of these arrhythmias during anesthesia in older horses and their impact on cardiovascular physiology has not been investigated.

The incidence of mitral insufficiency is not greater in older horses,${ }^{41}$ but the intensity of murmurs due to mitral insufficiency is reported to be greater in older horses. ${ }^{30}$ In a substantial proportion of horses presenting with severe mitral insufficiency, there is concurrent myocardial fibrosis and, in some of these animals, myocardial lesions are considered to be the primary disease leading to mitral insufficiency. ${ }^{41}$ Another study indicated that age was a significant risk factor for mortality associated with aortic and mitral insufficiency. ${ }^{32}$ Increases in left atrial pressure secondary to mitral regurgitation may result in an increase in left atrial diameter, and these horses have an increased risk of developing atrial fibrillation. ${ }^{31}$ Horses with pulmonary hypertension, as a sequela of mitral regurgitation, are at risk for sudden death secondary to rupture of the pulmonary artery. ${ }^{41}$ 


\section{Aortocardiac fistula}

Aortocardiac fistula, although first described as a disease of older stallions, is not unique to older horses. ${ }^{30,42,43}$ The etiology of this condition is unclear, but it occurs as a result of rupture of the right aortic sinus. The aorta ruptures directly into the right atrium or ventricle or forms a fistulous tract through the aortic ring or ventricular septum to the left or right ventricle or right atrium. Stallions older than 5 years of age are most commonly affected. ${ }^{43}$

\section{Age-associated vascular changes}

In aged humans, the vascular system is affected by a decrease in the tonic influence of the parasympathetic nervous system, and changes in the vascular wall. ${ }^{33,34}$ Vascular changes result in arterial and venous rigidity, an increase in systemic vascular resistance, and a decrease in venous compliance. Mineralization of the intimal layer of blood vessels is a common finding in the cerebral arteries, capillaries, and veins of old horses, although its clinical importance is not clear. ${ }^{44}$ The loss of elasticity in large arteries causes a progressive increase in systemic blood pressure and widening of pulse pressure. Increased sympathetic nervous system activity may also contribute to the increase in systemic vascular resistance. Age-associated vascular changes in horses are not well documented; however, in one study, there was no difference in arterial blood pressures in horses less than 15 years and those over 20 years. $^{5}$

A decrease in venous compliance decreases the ability to compensate for changes in intravascular volume, and exaggerates hypotension resulting from blood loss, or from peripheral pooling of blood observed during general or regional anesthesia. ${ }^{45,46}$ Other factors predisposing to hypotension may include diminished sensitivity of baroreceptor and beta receptors' response, and decreased response of the renin/aldosterone/angiotensin system in advanced age. ${ }^{45,47}$ Hypotension is one of the common complications during equine general anesthesia and these vascular changes may further predispose the geriatric horse to hypotension. However, in anesthetized horses, age did not have an effect on the response to dobutamine therapy, indicating that there was no decrease in the responsiveness of beta receptors. ${ }^{19}$ Nevertheless, preliminary data indicates that geriatric horses are more prone to the cardiovascular depressant effects of inhalational anesthetics. ${ }^{5}$

\section{Aging and the pulmonary system}

Several anatomical and physiological changes in the pulmonary system occur with aging. The main changes are increased compliance and decreased elastic recoil of the lungs, and decreased respiratory muscle function and chest wall compliance. Decreased chest compliance and lung recoil increases residual and closing volumes, and dead space ventilation. In elderly people, the dynamic lung compliance becomes frequency dependent. As breathing rate increases, lung expansion becomes less effective and ventilation to perfusion (V/Q) mismatch increases. ${ }^{1}$ A similar pathophysiology may be responsible, at least in part, for development of $\mathrm{V} / \mathrm{Q}$ mismatch in geriatric horses. These changes, along with a decrease in alveolar surface area and an increase in shunting, result in decreased gas exchange efficiency, decreased arterial oxygen partial pressures $\left(\mathrm{PaO}_{2}\right)$, and greater alveolar-arterial oxygen difference $(\mathrm{A}-\mathrm{a}$ difference). ${ }^{4,5}$ Decreased $\mathrm{PaO}_{2}$ and greater $(\mathrm{A}-\mathrm{a}) \mathrm{O}_{2}$ difference were reported in awake horses older than 20 years of age when compared to a group of younger horses. ${ }^{8}$ In that study, $\mathrm{PaCO}_{2}$ values in older horses were less, and the $\mathrm{pH}$ was greater, compared to the younger animals, indicating a compensatory hyperventilation.

In the elderly, loss of respiratory muscle fibers and a decrease in central and peripherally mediated ventilatory responses to changes in $\mathrm{PaO}_{2}$ and $\mathrm{CO}_{2}$ or airway stimulation have been reported, ${ }^{48}$ and are likely to occur to some degree in older horses. ${ }^{4,5}$ In recumbent horses under inhalational anesthesia, functional residual capacity and residual volume are reduced, and $\mathrm{PaO}_{2}$ values are often decreased, despite the use of maximal fraction of inspired oxygen. ${ }^{49,50}$

\section{Recurrent airway obstruction}

Recurrent airway obstruction (RAO) (heaves) is the most common respiratory disorder in older horses. ${ }^{51,52}$ This recurrent inflammatory condition can cause permanent pulmonary remodeling and fibrosis, if not treated initially. Airway smooth muscle and pulmonary epithelial hypertrophy may result in a net loss of intra-alveolar septae and pulmonary capillaries, with an increased number of intra-alveolar pores and deposition of collagen. Exercise intolerance, respiratory distress, chronic coughing, mucopurulent nasal discharge, abnormal pulmonary sounds, and an enlarged field of percussion are usually noted during physical examination. In these animals, pulmonary arterial pressure is increased, gas exchange is compromised, and end-expired lung volume is increased. ${ }^{53,54}$ Due to an overall decrease in respiratory functional reserve, greater $(\mathrm{A}-\mathrm{a}) \mathrm{O}_{2}$ difference and $\mathrm{V} / \mathrm{Q}$ mismatch, and lower $\mathrm{PaO}_{2}$ and $\mathrm{PaCO}_{2}$ values in geriatric horses, ${ }^{8}$ perioperative pulmonary function 
is of particular concern. The $\mathrm{PaO}_{2}$ is usually decreased, indicating impairment of pulmonary gas exchange. Therefore, providing mechanical ventilation during general anesthesia may correct blood gas abnormalities. As these horses usually suffer from increased pulmonary resistance, bronchodilators (beta-2 adrenergic agonists and parasympathomimetics) are efficacious in relieving smooth muscle contraction in the lower airways and the associated respiratory distress. ${ }^{55}$ The administration of bronchodilators, such as aerosolized albuterol, ${ }^{56}$ during anesthesia may improve oxygenation and ventilatory parameters. Recently, however, it has been shown that the S-enantiomer of salbutamol can elicit an increase in the contraction of equine airway smooth muscle on isolated equine bronchi; thus, only the R-enantiomer is recommended for use..$^{57}$

\section{Infectious pulmonary diseases}

Although bacterial pneumonia is independent of age, geriatric horses suffering from subclinical or undiagnosed pituitary pars intermedia dysfunction (PPID) and increased serum cortisol, are more prone to secondary bacterial pneumonia due to immunosuppression. Bacterial pulmonary disease may also occur secondary to upper airway viral pathogens and RAO.

\section{Aging and the musculoskeletal system}

Musculoskeletal diseases are among the most commonly reported clinical problems in aged horses. ${ }^{58}$ Periarticular degenerative diseases of the axial skeleton in aged horses may be sufficiently advanced to compromise spinal cord function. ${ }^{35}$ Osteoarthritic degenerative changes affect the overall function of the musculoskeletal system, and may compromise the quality of recovery from general anesthesia.

The loss of skeletal muscle and lean body mass that occurs with aging is referred to as sarcopenia. ${ }^{59}$ Sarcopenia encompasses the effects of changes in central and peripheral nervous system innervation, hormonal status, inflammation, altered caloric and protein intake, and cumulatively results in loss of muscle fiber and fiber atrophy. ${ }^{2,60}$ Sarcopenia is only now being recognized in veterinary patients. ${ }^{61}$ In humans, age-associated changes in muscle strength are directly correlated with the loss of skeletal muscle mass. A decrease of approximately $40 \%$ in total muscle cross-sectional area occurs in humans between the ages of 20 and 60 years. ${ }^{62,63}$ Significant age-related changes responsible for loss of muscle mass and strength may include changes in motor units, muscle fibers, and muscle protein. ${ }^{64-67}$ These changes affect spatial organization and physiological properties of fast- and slow-twitch single motor units, regulation of contractile speed and force generation capacity of muscle fibers, and functional properties of myosin. ${ }^{68}$ There is also a disorganization of coordinated expression of contractile, sarcoplasmic reticular and mitochondrial protein isoforms in aging skeletal muscle.$^{64}$ The net effect of aging on neuromuscular function is a reduction in contractile strength, proprioception, and coordination.

It is clear that many older horses lose muscle mass; however, many others remain active and appear well muscled. Decreased muscle mass in a horse will have a significant impact on the anesthetic outcome, as the horse's ability to stand during recovery may be compromised. Sarcopenia may also contribute to increased heat loss under general anesthesia. Lean animals lose core temperature faster than animals with sufficient muscle mass, and this is well demonstrated in elderly humans. ${ }^{69}$

\section{Aging and the endocrine system Cushing's disease (pituitary pars intermedia dysfunction - PPID)}

Cushing's disease, one of the most common endocrine abnormalities of older horses, is the consequence of glucocorticoids acting in excess of physiological requirements. ${ }^{70}$ The prevalence of Cushing's disease has increased during the past several years and has an incidence of $0.5 \%$. It is primarily observed in horses $18-21$ years old. ${ }^{71}$ Horses with Cushing's may be more sensitive to sedatives and anesthetics as a consequence of muscle wasting and fat redistribution. Also, corticosteroid-induced changes such as hepatopathy, immunosuppression, and osteoporosis may affect drug metabolism, pulmonary function (due to pneumonia), and the quality of recovery. ${ }^{71,72}$

Cardiopulmonary changes such as tachypnea, tachycardia, and hypertension are not uncommon in horses with Cushing's disease. ${ }^{72}$ The vascular smooth muscle may be more responsive to catecholamines ${ }^{73}$ and some of the cardiovascular instability present in geriatric animals may be counteracted in animals with Cushing's disease due to an overall increase in sensitivity of the cardiovascular system to adrenergic agents. However, vasoconstriction and hypovolemia may result in reduced tissue perfusion, and volume-loading of these animals prior to anesthesia is recommended. ${ }^{5}$ Secondary diabetes mellitus or insipidus, blood glucose, fluid, and electrolyte abnormalities may also be present in these horses, and hyperhidrosis may 
contribute to the hypovolemia and hypokalemia. ${ }^{70,72}$ Due to the catabolic effect of corticosteroids, these horses may be sarcopenic, thus, supporting ventilation and recovery may be necessary. ${ }^{5}$ Dopamine agonists or serotonin antagonists are used to treat Cushing's disease, and adverse effects such as hypotension, agitation, cardiac arrhythmias, and sedation have been reported with treatment. ${ }^{74-76}$

\section{Hypothyroidism}

Hypothyroidism is associated with aging in horses. ${ }^{4}$ Primary hypothyroidism, as an autoimmune disease, has been reported in specific instances in horses. ${ }^{70}$ Secondary hypothyroidism may be due to hyperadrenocorticism or surgical thyroidectomy. ${ }^{70,72}$ Physiological changes after surgical thyroidectomy in horses may include decreases in resting heart rate, cardiac output, respiratory rate, and body temperature, and slight increases in plasma and blood volume may be observed. Hypothyroidism may contribute to bradycardia and hypotension during anesthesia, and the beta adrenergic responses may also change, as the heart rate increase in response to isoproterenol was less in horses after thyroidectomy. ${ }^{77}$

Identification and treatment of the underlying cause (if any) of secondary hypothyroidism should be performed prior to anesthesia. Although thyroid hormone supplementation in horses is of unknown benefit, it may be beneficial in secondary hypothyroidism. ${ }^{78}$

In summary, full evaluation of endocrine abnormalities and correcting the imbalances should be performed prior to anesthesia, particularly for elective procedures.

\section{Pharmacological considerations in geriatrics}

The pharmacokinetics of anesthetic drugs in geriatric animals may be altered by changes in physiological parameters such as a decreased metabolic rate and cardiac output, increased ratio of fat to muscle tissue, decreased cerebral blood flow, a decrease in the concentration of plasma protein, and volume of distribution of particular drugs. ${ }^{79,80}$ In older people, smaller initial volumes of distribution and slower intercompartmental clearance rates, redistribution, metabolism, and excretion for propofol and thiopenthal are reported, and as much as a 50\% decrease in the dose may be indicated. ${ }^{79,81,82}$ It is suggested that geriatric horses may experience more intense and longer lasting analgesia with butorphanol and morphine for standing sedation. ${ }^{5}$ The decreased lean body mass in geriatric animals will cause a smaller amount of the drug to be directed into the muscles; ${ }^{83}$ thus, a greater fraction of the drug will reach the brain. There is a paucity of information on the effect of aging on these parameters in horses; but total protein and albumin concentrations in several groups of horses older than 20 years of age were similar to those of young horses. ${ }^{6,7}$

The pharmacodynamics of anesthetic drugs may be altered in geriatric animals due to changes in receptor sensitivity. Alterations in receptor activity of opioids and benzodiazepines have been documented in geriatric people. ${ }^{79,84}$ For instance, binding of the channel protein associated with NMDA receptors increases with age, ${ }^{85}$ and occupied benzodiazepine receptors create a relatively greater depression of neuronal activity. ${ }^{80}$ Age-related changes in brain NMDA receptor binding and a decrease in the MAC of isoflurane have been demonstrated in geriatric dogs. ${ }^{27}$

Clearance of most anesthetics is prolonged in the elderly. ${ }^{79}$ Recovery from anesthesia may be prolonged due to decreases in drug clearance and tissue perfusion, and a greater proportion of adipose tissue, which acts as a 'sink' for lipid soluble drugs.

A decrease in liver blood flow during anesthesia may also have a significant effect on the clearance of drugs with a high extraction ratio (eg, ketamine and morphine), because hepatic clearance is proportional to liver blood flow. ${ }^{79,86,87}$ In contrast, the clearance rate for anesthetic drugs with a low extraction ratio (eg, diazepam and thiopental) is limited by the metabolizing capacity of the liver. ${ }^{86}$ Hepatic clearance of benzodiazepines is slower in aged people; ${ }^{88}$ thus, repeated or large doses of benzodiazepines may prolong recovery.

There is an age-associated increase in sensitivity to opioids and a linear decrease in epidural dose requirements in people. ${ }^{89}$ Factors such as the anatomical changes influencing the size and patency of the intervertebral foramina, alterations in local blood flow, and changes in nerve fibers and their integuments inside and outside the spinal cord, are potential reasons for the difference in pharmacodynamics of epidurally administered opioids. This may also be the case in geriatric horses, as it was reported that a 25-year-old horse with an infected pelvic limb tendon sheath, required a smaller than expected dose of epidural morphine to control pain. ${ }^{5}$

Renal clearance of drugs may also be affected by the aging process, and although serum creatinine concentrations may be within the normal range in geriatric people, creatinine clearance may be decreased, ${ }^{79}$ indicating decreased renal reserve. In a study of healthy horses older than 20 years, no abnormality in serum urea nitrogen, creatinine, albumin, liver enzyme activities, and electrolytes was found $;^{7}$ creatinine clearance was however, not measured. 


\section{Anesthetic considerations in geriatric horses Anesthetic morbidity and mortality in geriatrics}

In humans, anesthetic associated morbidity and mortality increase with aging, ${ }^{1}$ and the same is true for horses. In a study of more than 41,000 horses, those aged 14 years or older were at greater risk of mortality (odds ratio of 1.42)..$^{90}$ The two main reasons for increased mortality in older horses were an increased risk of long-bone fracture during recovery, and an increased likelihood of co-existing diseases affecting the outcome..$^{90}$ In another study on more than 17,000 horses undergoing general anesthesia, there were $42(0.24 \%)$ perianesthetic fatalities. ${ }^{91}$ Although the relationship between age and mortality was not evaluated as a covariant in that study, the six Thoroughbred mares that fractured a long-bone during recovery were older (9-18 years). Older mares may be at an increased risk of long-bone fracture, as bone density studies have reported decreased metacarpal breaking strength in some older mares up to 40 weeks post-parturition. ${ }^{92}$

\section{Preanesthetic evaluation of the geriatric horse}

After obtaining a complete history of use, exercise tolerance, and ability to rise from recumbency, a thorough physical examination should be performed. A physical examination during rest and exercise has been suggested, because exercise may unmask diseases such as RAO and cardiac diseases that are not apparent at rest. In clinically healthy geriatric horses, the authors perform only basic laboratory tests (hematocrit and total protein determination); however, in sick horses a complete and differential blood count and biochemical analysis may be indicated. If significant cardiac murmurs or arrhythmias are present, a complete cardiac evaluation is recommended.

\section{Standing sedation}

Many procedures, such as surgery of sinuses, dental surgery, and laparoscopic surgery can be performed with the horse standing and sedated, in association with local or regional anesthesia. Standing surgery avoids the problems associated with general anesthesia and recovery, and should be performed, whenever possible, in geriatric horses.

\section{Drugs used for sedation}

\section{Acepromazine}

Does not give reliable sedation, and may cause hypotension, especially if large doses are used. Acepromazine has been mainly replaced by alpha-2 agonists, but small doses $(0.02 \mathrm{mg} / \mathrm{kg}, \mathrm{IV})$ can be combined with an alpha-2 agonist for more profound sedation and analgesia. ${ }^{4}$

\section{Opioids}

Opioids such as butorphanol, morphine, and meperidine, are not used alone for sedation because they may cause dysphoria or excitement, especially if given as a bolus IV to an unsedated horse; however, they have synergistic or additive analgesic and sedative effects with other drugs such as alpha- 2 agonists. Therefore, opioids are usually combined with alpha-2 agonists, as described below. Additionally, histamine release and hypotension may result, especially if meperidine is administered IV.

\section{Alpha-2 agonists}

This group of drugs provides dose-dependent sedation and analgesia, thus, they can be administered to effect. They also have the advantage of being reversible. In geriatric horses, the authors initially administer a small dose of an alpha-2 agonist (eg, xylazine $0.25-0.5 \mathrm{mg} / \mathrm{kg}, \mathrm{IV}$ ). Xylazine is the shortest acting alpha-2 agonist and, thus, may be most suitable for use in geriatric horses. Short-term sedation is usually achieved by administering an alpha-2 agonist as a bolus; however, a constant rate infusion (CRI) will give more reliable sedation for prolonged procedures. To provide more reliable sedation and analgesia, an alpha-2 agonist can be combined with an opioid. The alpha- 2 agonist bolus dose depends on the degree of sedation and analgesia required, and IV doses in the following ranges are recommended by the authors:

- Xylazine $(0.25-1 \mathrm{mg} / \mathrm{kg})$

- Detomidine $(0.0025-0.01 \mathrm{mg} / \mathrm{kg})$

- Romifidine $(0.025-0.1 \mathrm{mg} / \mathrm{kg})$

- Dexmedetomidine (0.0015-0.0025 mg/kg).

If combining alpha-2 agonists with an opioid, it is important that the horse is sedated before the opioid is administered, to prevent opioid-induced excitement. In addition, it is important to administer the drugs slowly, and in increments, to achieve the desired effect and avoid excessive sedation and ataxia.

The authors suggest the following IV drug doses when combining alpha-2 agonists and opioids:

- Xylazine (0.25-1.0 mg/kg) plus butorphanol (0.01$0.02 \mathrm{mg} / \mathrm{kg})$ or morphine $(0.1 \mathrm{mg} / \mathrm{kg})$

- Detomidine $(0.0025-0.005 \mathrm{mg} / \mathrm{kg})$ plus butorphanol $(0.01-0.02 \mathrm{mg} / \mathrm{kg})$ or morphine $(0.1 \mathrm{mg} / \mathrm{kg})$

- Romifidine (0.03-0.06 mg/kg) plus butorphanol (0.01$0.02 \mathrm{mg} / \mathrm{kg})$ or morphine $(0.1 \mathrm{mg} / \mathrm{kg})$ 
- Dexmedetomidine $(0.001-0.002 \mathrm{mg} / \mathrm{kg}$ ) plus butorphanol $(0.01-0.02 \mathrm{mg} / \mathrm{kg})$ or morphine $(0.1 \mathrm{mg} / \mathrm{kg})$.

\section{Constant rate infusions}

Constant rate infusions (CRI) are used to deliver sedativeanalgesic drugs when prolonged sedation-analgesia is required, as when surgery is performed on a standing horse. A CRI provides a more steady state of sedation than intermittent bolus administration of a drug(s). A CRI can be delivered by adding the drug(s) to a bag of balanced electrolyte solution and determining the drip rate; however, to be more accurate, the drugs can be delivered using a syringe pump or fluid pump. A loading dose $(\mathrm{Ld})$ is delivered initially, and the CRI is then started. Alpha-2 doses in the following ranges are recommended:

- Xylazine: $\mathrm{Ld}=0.25-1 \mathrm{mg} / \mathrm{kg}$ IV and a CRI = $0.5-1.0 \mathrm{mg} / \mathrm{kg} / \mathrm{hour}$

- Detomidine: $\mathrm{Ld}=0.0025-0.01 \mathrm{mg} / \mathrm{kg}$ IV and a CRI $=0.01-0.02 \mathrm{mg} / \mathrm{kg} / \mathrm{hour}$

- Dexmedetomidine: $\mathrm{Ld}=0.0015-0.0025 \mathrm{mg} / \mathrm{kg}$ IV and a CRI of $0.0015-0.0025 \mathrm{mg} / \mathrm{kg} / \mathrm{hour}$

- Romifidine: Ld $=0.03-0.1 \mathrm{mg} / \mathrm{kg}$ IV and a CRI $=0.01-0.02 \mathrm{mg} / \mathrm{kg} /$ hour.

If an opioid is added, the dose of the alpha- 2 agonist is decreased to avoid excessive sedation and ataxia. Doses in the following range are used by the authors:

- Detomidine: $\mathrm{Ld}=0.0025-0.005 \mathrm{mg} / \mathrm{kg}$ IV and a CRI $=0.01 \mathrm{mg} / \mathrm{kg} /$ hour, plus

- Butorphanol: $\mathrm{Ld}=0.01-0.02 \mathrm{mg} / \mathrm{kg}$, IV and a $\mathrm{CRI}=0.012 \mathrm{mg} / \mathrm{kg} /$ hour or morphine: $\mathrm{Ld}=0.10 \mathrm{mg} / \mathrm{kg}$, IV over 10 minutes, and a CRI $=0.15 \mathrm{mg} / \mathrm{kg} /$ hour.

Detomidine is the most frequently used alpha- 2 agonist, but others may be used in place of detomidine. For most procedures lasting less than 2 hours, the authors just use a loading dose of morphine without a CRI. It is especially important in geriatric horses that the loading dose of morphine be administered slowly to avoid excessive sedation.

\section{Reversal of alpha- 2 agonists}

Yohimbine and atipamezole are the most commonly used alpha-2 antagonists. Because alpha-2 antagonists can induce serious adverse effects, including hypotension, airway edema, and excitation, they must be administered slowly. Yohimbine is a less specific antagonist, and can be used in doses of $0.025-0.05 \mathrm{mg} / \mathrm{kg}$, given slowly IV. The authors usually administer yohimbine over 10 minutes. The mean effective half-life of yohimbine is about 1 hour, and this prevents relapse of sedation in most horses..$^{93}$ The affinity of atipamezole for alpha- 2 receptors is 100 times greater than that of other antagonists, and the authors use a dose of $0.02-0.04 \mathrm{mg} / \mathrm{kg}$, IV over 10 minutes.

\section{Induction of anesthesia}

There are a limited number of drug combinations for induction of anesthesia. Although it may be best to administer induction drugs to effect, the size of the horse makes this impractical. In any case, geriatric horses tolerate induction of anesthesia quite well if cardiovascularly stable.

\section{Induction regimens}

\section{Ketamine and a benzodiazepine}

This is the most common regimen for induction of anesthesia, after sedation with an alpha-2 agonist (eg, xylazine 0.5$1.0 \mathrm{mg} / \mathrm{kg}$ ). For this purpose, ketamine $(1.5-2.2 \mathrm{mg} / \mathrm{kg}$ ) and diazepam or midazolam $(0.02-0.1 \mathrm{mg} / \mathrm{kg})$ can be combined in the same syringe and administered as a bolus. ${ }^{4}$ The benzodiazepine improves muscle relaxation and sedation.

\section{Guaiphenesin and ketamine}

Guaiphenesin, a centrally acting muscle relaxant, is generally administered as a $5 \%$ solution. It is used to facilitate induction of anesthesia in the sedated horse, and many clinicians include guaiphenesin in the regimen in order to decrease the dose of alpha- 2 agonist. Guaiphenesin can be administered by one of two methods: after the horse becomes sedated, guaiphenesin $(30-50 \mathrm{mg} / \mathrm{kg}, \mathrm{IV})$ is administered rapidly until the horse becomes ataxic, at which point, ketamine is administered as a bolus. Alternatively, ketamine can be mixed with the guaiphenesin, and the mixture given to effect until recumbency. Although this allows the mixture to be given somewhat to effect, it is important to administer approximately half of the mixture rapidly to avoid excessive ataxia. $^{4}$

\section{Maintenance of anesthesia}

General anesthesia can be maintained with inhalational, total intravenous anesthesia or partial intravenous anesthesia. Inhalational anesthesia is the most common method of maintaining anesthesia. The MAC of inhalational anesthetics is likely to be $10 \%-20 \%$ less in geriatric horses. Inhalational anesthetics generally cause hypotension, ${ }^{94,95}$ and geriatric patients may be more prone to hypotension. ${ }^{5}$ 


\section{Total intravenous anesthesia (TIVA)}

Drug kinetics may be altered in geriatric horses, and drug accumulation may occur during long infusions; thus, decreasing the infusion rate over time may manage this problem. Nevertheless, the authors have used TIVA, without complication, in older horses. These horses may remain recumbent for longer after TIVA, but the recoveries are generally more controlled than with inhalational anesthetics. Another advantage of TIVA is the decreased incidence of intraoperative hypotension.

Anesthesia can be induced as described above. The most commonly used drug combination is ketamine and an alpha-2 agonist with guaiphenesin. The authors suggest that ketamine (1-1.5 g) and xylazine $(500 \mathrm{mg})$ be added to $1 \mathrm{~L}$ of a $5 \%$ solution of guaiphenesin and infused at the rate of $2-3 \mathrm{~mL} / \mathrm{kg}$ /hour. This mixture is also known as triple drip. Because guaiphenesin is cleared slowly it may contribute to weakness in recovery; thus, the authors recommend that it only be administered for the first hour. Beyond this time, anesthesia is maintained with ketamine and xylazine diluted in a balanced electrolyte solution.

\section{Partial intravenous anesthesia (PIVA)}

This is the combination of inhalational and intravenous anesthetics, and has been used successfully by the authors in geriatric horses. In the authors' hospital, ketamine (2-2.5 mg/ $\mathrm{kg} /$ hour), xylazine ( $0.25 \mathrm{mg} / \mathrm{kg} /$ hour), and lidocaine (3-6 mg/kg/hour) are used in conjunction with isoflurane at an end-tidal concentration of $0.5 \%$. A loading dose of lidocaine ( $3 \mathrm{mg} / \mathrm{kg}$ over 15 minutes) is followed by an infusion of $6 \mathrm{mg} / \mathrm{kg}$ /hour for the first hour, and $3 \mathrm{mg} / \mathrm{kg}$ /hour in subsequent hours. Intraoperative analgesia and a decreased incidence of hypotension are the main advantages of PIVA.

\section{Respiratory support during general anesthesia in geriatric horses}

In horses with recurrent airway obstruction, the medications used to modify airway resistance and responsiveness, such as beta- 2 agonists, must not be withheld preoperatively. ${ }^{5}$ Controlled mechanical ventilation is recommended, because the adaptive active abdominal phase of expiration, in response to greater airway resistance, is lost under general anesthesia. These animals are prone to alveolar hyperinflation and increased intrathoracic pressure, thus, during mechanical ventilation, the expiratory time should be sufficiently long to allow for a full expiration. ${ }^{5}$ Moderate permissive hypercapnea, and use of a pressure-cycled ventilator, in contrast to volume-cycled ventilator, may help prevent progressive hyperinflation of the lung. ${ }^{5}$ Supporting ventilation and oxygenation during recovery is also important, and can be achieved by using an oxygen demand valve.

\section{Anesthetic concerns in geriatric horses with musculoskeletal disorders}

Horses with significant musculoskeletal abnormalities (eg, osteoarthritis and sarcopenia) are at increased risk of anesthetic complications. The decrease in metabolic rate and muscle mass predispose to hypothermia; thus, active heating may be indicated. Padding and proper positioning are very important in optimizing the outcome. Assistance during recovery may be necessary due to muscle weakness and osteoarthritis. ${ }^{5}$ The authors routinely use head and tail ropes to assist recovery in geriatric horses.

\section{Anesthetic monitoring and pain control in geriatric animals}

Monitoring during anesthesia is important because geriatric horses may have limited physiological reserve. The minimum anesthetic monitoring includes assessment of anesthetic depth and indicators of cardiopulmonary function (capillary refill time, pulse quality, and rhythm). Arterial blood pressure measurement, preferably a direct measurement, is recommended. A minimum mean blood pressure of $70 \mathrm{mmHg}$ should be maintained, using an inotrope (eg, dobutamine), if necessary. The ECG should be monitored closely due to the increased incidence of arrhythmias in older horses, and arterial blood gases analysis monitoring is advisable due to the increased incident of hypoxemia in this age group.

Control of pain in geriatric animals, especially those that may suffer from underlying painful conditions such as musculoskeletal diseases or those that undergo surgical procedures, has a significant role in assuring a more favorable anesthetic outcome. Preoperative administration of nonsteroidal anti-inflammatory drugs, if not contraindicated, intraoperative administration of analgesics as components of TIVA or PIVA, and the use of local-regional blocks, are among the techniques that can be recommended to control perianesthetic pain and minimize the stress response.

In summary, age-associated physiological changes in geriatric horses make them prone to anesthetic complications. However, by administering a balanced anesthesia regimen, closely monitoring of body systems during anesthesia, and assisting with recovery, as well as controlling pain, the anesthetic outcome can be optimized. 


\section{Disclosure}

The authors report no conflicts of interest in this work.

\section{References}

1. Sophie S. Anaesthesia for the elderly patient. J Pak Med Assoc. 2007; 57(4):196-201.

2. Doherty TJ. Invited review: Aging and sarcopenia. J Appl Physiol. 2003;95(4):1717-1727.

3. Traub-Dargatz JL, Long RE, Bertone JJ. What is an 'old horse' and its recent impact. In: Bertone JJ, editor. Equine Geriatric Medicine and Surgery. St Louis, MO: Saunders Elsevier; 2006:1-4.

4. Donaldson LL. Anesthesia of the geriatric horse. In: Doherty TJ, Valverde A, editors. Manual of Equine Anesthesia and Analgesia. Ames, IA: Blackwell; 2006:237-243.

5. Donaldson LL. Anesthetic Considerations for the Geriatric Equine. In: Bertone JJ, editor. Equine Geriatric Medicine and Surgery. St Louis, MO: Saunders Elsevier; 2006:25-37.

6. Ralston SL, Nockels CF, Squires EL. Differences in diagnostic test results and hematologic data between aged and young horses. Am J Vet Res. 1988;49(8):1387-1392.

7. McFarlane D, Sellon DC, Gaffney D, Hedgpeth V, Papich M, Gibbs S. Hematologic and serum biochemical variables and plasma corticotropin concentration in healthy aged horses. Am J Vet Res. 1998;59(10): 1247-1251.

8. Aguilera-Tejero E, Estepa JC, Lopez I, Mayer-Valor R, Rodriguez M. Arterial blood gases and acid-base balance in healthy young and aged horses. Equine Vet J. 1998;30(4):352-354.

9. Tasch MD. The autonomic nervous system and geriatric anesthesia. Int Anesthesiol Clin. 1988;26(2):143-151.

10. Kazmers A, Perkins AJ, Jacobs LA. Outcomes after abdominal aortic aneurysm repair in those $>$ or $=80$ years of age: recent Veterans Affairs experience. Ann Vasc Surg. 1998;12(2):106-112.

11. Fisher MB, Birren JE. Age and strength. J Appl Psychol. 1947;31(5): 490-497.

12. Doherty TJ, Brown WF. The estimated numbers and relative sizes of thenar motor units as selected by multiple point stimulation in young and older adults. Muscle Nerve. 1993;16(4):355-366.

13. Evans WJ. Effects of exercise on senescent muscle. Clin Orthop Relat Res. 2002;403 Suppl:S211-S220.

14. Chakrabarti S, Munshi S, Banerjee K, Thakurta IG, Sinha M, Bagh MB. Mitochondrial Dysfunction during Brain Aging: Role of Oxidative Stress and Modulation by Antioxidant Supplementation. Aging Dis. 2011;2(3):242-256.

15. Capucchio MT, Marquez M, Pregel P, et al. Parenchymal and vascular lesions in ageing equine brains: histological and immunohistochemical studies. J Comp Pathol. 2010;142(1):61-73.

16. Chetelat G, Villemagne VL, Villain N, et al. Accelerated cortical atrophy in cognitively normal elderly with high beta-amyloid deposition. Neurology. 2012;78(7):477-484.

17. Kline RP, Pirraglia E, Cheng H, et al. Surgery and brain atrophy in cognitively normal elderly subjects and subjects diagnosed with mild cognitive impairment. Anesthesiology. 2012;116(3):603-612.

18. Butler RN. Brain preservation. Geriatrics. 1998;53(11):3-4.

19. Donaldson LL. Retrospective assessment of dobutamine therapy for hypotension in anesthetized horses. Vet Surg. 1988;17(1):53-57.

20. Delorey DS, Clifford PS, Mittelstadt S, et al. The effect of aging on adrenergic and nonadrenergic receptor expression and responsiveness in canine skeletal muscle. J Appl Physiol. 2012;112(5):841-848.

21. Mooradian AD. Effect of aging on the blood-brain barrier. Neurobiol Aging. 1988;9(1):31-39.

22. Gregory GA, Eger EI 2nd, Munson ES. The relationship between age and halothane requirement in man. Anesthesiology. 1969;30(5):488-491.

23. Yamashita K, Iwasaki Y, Umar MA, Itami T. Effect of age on minimum alveolar concentration (MAC) of sevoflurane in dogs. J Vet Med Sci. 2009;71(11):1509-1512.
24. Katoh T, Suguro Y, Ikeda T, Kazama T, Ikeda K. Influence of age on awakening concentrations of sevoflurane and isoflurane. Anesth Analg. 1993;76(2):348-352.

25. Lerman J, Schmitt-Bantel BI, Gregory GA, Willis MM, Eger EI 2nd. Effect of age on the solubility of volatile anesthetics in human tissues. Anesthesiology. 1986;65(3):307-311.

26. Lerman J, Gregory GA, Willis MM, Eger EI 2nd. Age and solubility of volatile anesthetics in blood. Anesthesiology. 1984;61(2): 139-143.

27. Magnusson KR, Scanga C, Wagner AE, Dunlop C. Changes in anesthetic sensitivity and glutamate receptors in the aging canine brain. J Gerontol A Biol Sci Med Sci. 2000;55(9):B448-B454.

28. Moller JT, Cluitmans P, Rasmussen LS, et al. Long-term postoperative cognitive dysfunction in the elderly ISPOCD1 study. ISPOCD investigators. International Study of Post-Operative Cognitive Dysfunction. Lancet. 1998;351(9106):857-861.

29. Monk TG, Weldon BC, Garvan CW, et al. Predictors of cognitive dysfunction after major noncardiac surgery. Anesthesiology. 2008; 108(1):18-30.

30. Marr CM, Bowen M. Cardiac Disease in the Geriatric Horse. In: Bertone JJ, editor. Equine Geriatric Medicine and Surgery. St Louis, MO: Saunders Elsevier; 2006:39-49.

31. Sage AM. Cardiac disease in the geriatric horse. Vet Clin North Am Equine Pract. 2002;18(3):575-589, viii.

32. Stevens KB, Marr CM, Horn JN, et al. Effect of left-sided valvular regurgitation on mortality and causes of death among a population of middle-aged and older horses. Vet Rec. 2009;164(1):6-10.

33. Rooke GA. Cardiovascular aging and anesthetic implications. J Cardiothorac Vasc Anesth. 2003;17(4):512-523.

34. Rooke GA. Autonomic and cardiovascular function in the geriatric patient. Anesthesiol Clin North America. 2000;18(1):31-46, v-vi.

35. Rooney JR, Robertson JL. Equine Pathology. Ames, IA: Iowa State University Press; 1996.

36. Amar D, Zhang H, Leung DH, Roistacher N, Kadish AH. Older age is the strongest predictor of postoperative atrial fibrillation. Anesthesiology. 2002;96(2):352-356.

37. McKeever KH, Malinowski K. Exercise capacity in young and old mares. Am J Vet Res. 1997;58(12):1468-1472.

38. Betros CL, McKeever KH, Kearns CF, Malinowski K. Effects of ageing and training on maximal heart rate and $\mathrm{VO}_{2 \max }$. Equine Vet J Suppl. 2002;34:100-105.

39. Else RW, Holmes JR. Cardiac pathology in the horse. 1. Gross pathology. Equine Vet J. 1972;4(1):1-8.

40. Reef VB. Heart murmurs in horses: determining their significance with echocardiography. Equine Vet J Suppl. 1995;19:71-80.

41. Reef VB, Bain FT, Spencer PA. Severe mitral regurgitation in horses: clinical, echocardiographic and pathological findings. Equine Vet J. 1998;30(1):18-27.

42. Lester GD, Lombard CW, Ackerman N. Echocardiographic detection of a dissecting aortic root aneurysm in a thoroughbred stallion. Vet Rad Ultrasound. 1992;33(4):202-205.

43. Marr CM, Reef VB, Brazil TJ, et al. Aorto-cardiac fistulas in seven horses. Vet Radiol Ultrasound. 1998;39(1):22-31.

44. Fankhauser R, Luginbuhl H, McGrath JT. Cerebrovascular disease in various animal species. Ann NY Acad Sci. 1965;127(1):817-860.

45. Rooke GA, Freund PR, Jacobson AF. Hemodynamic response and change in organ blood volume during spinal anesthesia in elderly men with cardiac disease. Anesth Analg. 1997;85(1):99-105.

46. Sharrock NE, Bading B, Mineo R, Blumenfeld JD. Deliberate hypotensive epidural anesthesia for patients with normal and low cardiac output. Anesth Analg. 1994;79(5):899-904.

47. Francis JJ. Surgery in the Elderly. In: Goldman DR, Brown FH, Guarneri DM, editors. Peri-operative Medicine. 2nd ed. New York: McGraw-Hill Inc; 1994:385-394.

48. Zaugg M, Lucchinetti E. Respiratory function in the elderly. Anesthesiol Clin North America. 2000;18(1):47-58, vi. 
49. Whitehair KJ, Willits NH. Predictors of arterial oxygen tension in anesthetized horses: 1,610 cases (1992-1994). J Am Vet Med Assoc. 1999;215(7):978-981.

50. Hubbell JA, Aarnes TK, Bednarski RM, Lerche P, Muir WW. Effect of $50 \%$ and maximal inspired oxygen concentrations on respiratory variables in isoflurane-anesthetized horses. BMC Vet Res. 2011;7:23.

51. Williamson KK, Davis MS. Evidence-based respiratory medicine in horses. Vet Clin North Am Equine Pract. 2007;23(2):215-227.

52. Davis E, Rush BR. Respiratory Disease in the Geriatric Equine Patient In: Bertone JJ, editor. Equine Geriatric Medicine and Surgery. St Louis, MO: Saunders Elsevier; 2006:179-192.

53. Robinson NE, Derksen FJ, Olszewski MA, Buechner-Maxwell VA. The pathogenesis of chronic obstructive pulmonary disease of horses. Br Vet J. 1996;152(3):283-306.

54. Nyman G, Lindberg R, Weckner D, et al. Pulmonary gas exchange correlated to clinical signs and lung pathology in horses with chronic bronchiolitis. Equine Vet J. 1991;23(4):253-260.

55. Robinson NE. International Workshop on Equine Chronic Airway Disease. Michigan State University June 16-18, 2000. Equine Vet J. 2001;33(1):5-19.

56. Derksen FJ, Olszewski MA, Robinson NE, et al. Aerosolized albuterol sulfate used as a bronchodilator in horses with recurrent airway obstruction. Am J Vet Res. 1999;60(6):689-693.

57. Matera MG, Calzetta L, Rogliani P, Bardaro F, Page CP, Cazzola M. Evaluation of the effects of the R- and S-enantiomers of salbutamol on equine isolated bronchi. Pulm Pharmacol Ther. 2011;24(2): 221-226.

58. Brosnahan MM, Paradis MR. Demographic and clinical characteristics of geriatric horses: 467 cases (1989-1999). J Am Vet Med Assoc. 2003; 223(1):93-98.

59. Evans WJ. What is sarcopenia? J Gerontol A Biol Sci Med Sci. 1995; 50 Spec No:5-8.

60. Welle S. Cellular and molecular basis of age-related sarcopenia. Can J Appl Physiol. 2002;27(1):19-41.

61. Freeman LM. Cachexia and sarcopenia: emerging syndromes of importance in dogs and cats. J Vet Intern Med. 2012;26(1):3-17.

62. Doherty TJ, Vandervoort AA, Brown WF. Effects of ageing on the motor unit: a brief review. Can J Appl Physiol. 1993;18(4):331-358.

63. Porter MM, Vandervoort AA, Lexell J. Aging of human muscle: structure, function and adaptability. Scand J Med Sci Sports. 1995;5(3):129-142.

64. Larsson L, Yu F, Hook P, Ramamurthy B, Marx JO, Pircher P. Effects of aging on regulation of muscle contraction at the motor unit, muscle cell, and molecular levels. Int J Sport Nutr Exerc Metab. 2001; 11 Suppl:S28-S43.

65. Alnaqeeb MA, Goldspink G. Changes in fibre type, number and diameter in developing and ageing skeletal muscle. J Anat. 1987;153:31-45.

66. Hooper AC. Length, diameter and number of ageing skeletal muscle fibres. Gerontology. 1981;27(3):121-126.

67. Campbell MJ, McComas AJ, Petito F. Physiological changes in ageing muscles. J Neurol Neurosurg Psychiatry. 1973;36(2):174-182.

68. Larsson L, Salviati G. Effects of age on calcium transport activity of sarcoplasmic reticulum in fast- and slow-twitch rat muscle fibres. J Physiol. 1989;419:253-264.

69. Kenney WL, Buskirk ER. Functional consequences of sarcopenia: effects on thermoregulation. J Gerontol A Biol Sci Med Sci. 1995; 50 Spec No:78-85.

70. Messer NTT, Johnson PJ. Evidence-based literature pertaining to thyroid dysfunction and Cushing's syndrome in the horse. Vet Clin North Am Equine Pract. 2007;23(2):329-364.

71. van der Kolk H. Diseases of the pituitary gland, including hyperadrenocorticism. In: Watson TDG, editor. Metabolic and Endocrine Problems of the Horse. New York: WB Saunders; 1998.

72. Love S. Equine Cushing's disease. Br Vet J. 1993;149(2):139-153.

73. Lampe GH, Roizen MF. Anesthesia for patients with abnormal function of the adrenal cortex. Anesth Clin North Am. 1987;5(2):245-267.
74. Dybdal N, Levy M. Pituitary pars intermedia dysfunction in the horse. Part II: diagnosis and treatment. Paper presented at: Presented at the 15th Annual Forum of the College of Veterinary Internal Medicine. Lake Buena Vista, FL; 1997.

75. Donaldson MT, LaMonte BH, Morresey P, Smith G, Beech J. Treatment with pergolide or cyproheptadine of pituitary pars intermedia dysfunction (equine Cushing's disease). J Vet Intern Med. 2002;16(6): 742-746.

76. Sojka JE. Hypothyroidism in horses. Compend Contin Edu Prac Vet. 1995; 17:845-852.

77. Vischer CM, Foreman JH, Constable PD, et al. Hemodynamic effects of thyroidectomy in sedentary horses. Am J Vet Res. 1999;60(1):14-21.

78. Frank N, Sommardahl CS, Eiler H, Webb LL, Denhart JW, Boston RC. Effects of oral administration of levothyroxine sodium on concentrations of plasma lipids, concentration and composition of very-low-density lipoproteins, and glucose dynamics in healthy adult mares. Am J Vet Res. 2005;66(6):1032-1038.

79. Shafer SL. The pharmacology of anesthetic drugs in elderly patients. Anesthesiol Clin North America. 2000;18(1):1-29, v.

80. Barnhill JG, Greenblatt DJ, Miller LG, Gaver A, Harmatz JS, Shader RI. Kinetic and dynamic components of increased benzodiazepine sensitivity in aging animals. J Pharmacol Exp Ther. 1990;253(3):1153-1161.

81. SchniderTW, Minto CF, Shafer SL, et al. The influence of age on propofol pharmacodynamics. Anesthesiology. 1999;90(6):1502-1516.

82. Stanski DR, Maitre PO. Population pharmacokinetics and pharmacodynamics of thiopental: the effect of age revisited. Anesthesiology. 1990;72(3):412-422.

83. Delp MD, Evans MV, Duan C. Effects of aging on cardiac output, regional blood flow, and body composition in Fischer-344 rats. $J$ Appl Physiol. 1998;85(5):1813-1822.

84. Mrak RE, Griffin ST, Graham DI. Aging-associated changes in human brain. J Neuropathol Exp Neurol. 1997;56(12):1269-1275.

85. Magnusson KR. Differential effects of aging on binding sites of the activated NMDA receptor complex in mice. Mech Ageing Dev. 1995;84(3):227-243.

86. Gupta DK, Henthorn TK. Pharmacologic principles. In: Barash PG, Cullen BF, Stoelting RK, Cahalan MK, editors. Clinical Anesthesia. Philadelphia, PA: Lippincott Williams \& Wilkins; 2009:143-144.

87. Landrum AL. Use of intravenous techniques in the elderly. In: White PF, editor. Textbook of Intravenous Anesthesia. Baltimore, MD: Lippincott Williams \& Wilkins; 1997.

88. Macklon AF, Barton M, James O, Rawlins MD. The effect of age on the pharmacokinetics of diazepam. Clin Sci (Lond). 1980;59(6): 479-483.

89. Bromage PR. Ageing and epidural dose requirements: segmental spread and predictability of epidural analgesia in youth and extreme age. $\mathrm{Br} \mathrm{J}$ Anaesth. 1969;41(12):1016-1022.

90. Johnston GM, Eastment JK, Wood JLN, Tylor PM. The confidential enquiry into perioperative equine fatalities (CEPEF): mortality results of Phases 1 and 2. Vet Anesth Analg. 2002;29:159-170.

91. Bidwell LA, Bramlage LR, Rood WA. Equine perioperative fatalities associated with general anaesthesia at a private practice - a retrospective case series. Vet Anaesth Analg. 2007;34(1):23-30.

92. Glade MJ. Effects of gestation, lactation, and maternal calcium intake on mechanical strength of equine bone. J Am Coll Nutr. 1993;12(4): 372-377.

93. Jernigan AD, Wilson RC, Booth NH, Hatch RC, Akbari A. Comparative pharmacokinetics of yohimbine in steers, horses and dogs. Can $\mathrm{J}$ Vet Res. 1988;52(2):172-176.

94. Malan TP Jr, DiNardo JA, Isner RJ, et al. Cardiovascular effects of sevoflurane compared with those of isoflurane in volunteers. Anesthesiology. 1995;83(5):918-928.

95. Bernard JM, Wouters PF, Doursout MF, Florence B, Chelly JE, Merin RG. Effects of sevoflurane and isoflurane on cardiac and coronary dynamics in chronically instrumented dogs. Anesthesiology. 1990;72(4): 659-662. 


\section{Publish your work in this journal}

Veterinary Medicine: Research and Reports is an international, Visit http://www.dovepress.com/testimonials.php to read real quotes peer-reviewed, open access journal publishing original research, from published authors.

case reports, editorials, reviews and commentaries on all areas of veterinary medicine. The manuscript management system is completely online and includes a very quick and fair peer-review system.

Submit your manuscript here: http://www.dovepress.com/veterinary-medicine-research-and-reports-journal 